\title{
Short communication \\ A comparative study on field performance of micropropagated plants and stem cutting derived plants of S-36 cultivar of Mulberry (Morus indica L.)
}

\author{
D S Vijaya Chitra1,*, Bhaskarrao Chinthapalli1, and G Padmaja ${ }^{2}$ \\ ${ }^{1}$ College of Natural Sciences, Department of Biology, Arba Minch University, Arba Minch, P.O. \\ Box 21, Ethiopia \\ 2Department of Plant Sciences, School of Life Sciences, University of Hyderabad, \\ Prof. C.R Rao Road, Gachibowli, Hyderabad, Andhra Pradesh 500046. \\ ${ }^{*}$ Corresponding author Email: dsvijaya.chitra@gmail.com
}

Micropropagated and stem cutting derived plants of Mulberry (Morus indica L. cv. S36) were transferred to the similar field conditions. A comparative study was conducted based on morphological parameters and growth characteristics for three consecutive years. The results demonstrated that micropropagation gave rise to superior clonal populations with respect to number of branches/plant and leaf yield/plant that will be suitable for the mass production of plants. Thus in vitro grown plants did not exhibit any significant quantitative variation as compared to the conventionally grown plants, indicating the varietal multiplication to be of true-to-type.

Key words. Micropropagated plants, Stem cutting derived plants, S-36 cultivar, field performance

Abbreviations : BAP - 6-benzyl amino purine; 2,4-D $\quad-$ 2, 4-Dichlorophenoxyacetic acid; $\mathrm{HgCl}_{2}$ - Mercuric chloride; IAA - Indole-3-acetic acid; MS - Murashige and Skoog's medium; MP - Micropropagated Plants; CP - Stem cutting derived Plants

Mulberry is an indispensable crop for the sericulture industry as it serves as the exclusive source of feed for silkworms (Bombyx mori L.). Mulberry plant regenerates itself naturally by seeds or propagated through cuttings or graftings. Propagation through seeds is undesirable as enormous heterozygosity prevails in mulberry plant owing to its cross-pollination (Das, 1983). The mass clonal propagation of mulberry through cuttings is a potentially valuable method to accelerate the improvement programmes of this important woody species (Yadav et al., 1990). However, most of the protocols are genotype specific and may not be applicable to valuable genotypes (Bhojwani, 1992). Methods of conventional vegetative propagation through grafting are not economically viable since it involves skilled manpower, expensive nursery facilities and a minimum time period of 4-5 years to obtain plants ready for harvest (Bhau, 1999).

The problems faced by the plant breeders in propagating this plant by conventional methods are overcome by using the applications of tissue culture technology. Tissue culture techniques such as 
micropropagation provide an alternative to the routine vegetative propagation of woody species with desirable traits (Biondi and Thorpe, 1982; Thorpe, 1983). In vitro plant regeneration from the apical/axillary shoot buds and nodal explants has been reported in a number of species of mulberry (Mhatre et al., 1985; Ohyama and Oka, 1987; Sharma and Thorpe, 1990; Chattopadhayay et al., 1990; Hossain et al., 1992; Tewari et al., 1995; Pattnaik and Chand, 1997; Chitra and Padmaja, 1999, 2002). Although micropropagation of mulberry is routinely done in research, relatively few results concerning the performance of micropropagated mulberry in field conditions have been published. The present study was undertaken to assess the field performance of micropropagated plants in comparison to stem cutting derived plants for growth characteristics and vegetative morphology for 3 consecutive years.

\section{Materials and Methods}

Mulberry cultivar S-36 (Morus indica L.) was procured from Department of Sericulture, P2, L. R. Seed Farm, Kammadanam, Mahboobnagar, Andhra Pradesh, India. S-36 cultivar was more tolerant to leaf sport and powdery mildew, moderately susceptible to leaf rust and tukra infestation. Most suitable to young age silkworm rearing. Moderate rooting ability.

For in vitro studies, nodal explants of $3-4 \mathrm{~cm}$ in length were collected from the same plants as described above. The nodal explants were kept under running tap water for half an hour and surface sterilized in 70\% alcohol for $1 \mathrm{~min}$ followed by $0.1 \%$ mercuric chloride $\left(\mathrm{HgCl}_{2}\right)$ for $15 \mathrm{~min}$ under sterile conditions. The explants were then rinsed 4-5 times in sterile distilled water with duration of $5 \mathrm{~min}$ each. The sterilized explants were placed on MS (Murashige and Skoog, 1962) medium containing 3\% sucrose and $0.8 \%$ agar. The culture medium was supplemented individually with 2,4-D varied concentrations for inducing sprouting and shoot differentiation. For multiplication of shoots, shoot tips of $2-3 \mathrm{~cm}$ derived from sprouted axillary buds were cultured on MS medium supplemented BAP at $0.5 \mathrm{mg} / 1$ for induction of multiple shoots.

Healthy shoots derived from the multiple shoots were transferred to MS medium supplemented $1.0 \mathrm{mg} / 1$ of 2,4-D for root induction. For acclimatization, regenerated plants having well developed roots were removed from culture bottles and washed free of agar. They were transferred to plastic pots containing soil and organic manure (3:1) and kept in a net house under shade for 15 - 20 days. In the first week of transfer, the plantlets were covered with polythene covers to maintain humidity. After 15-20 days of acclimatization, the plantlets were transferred to earthen pots and planted out in field.

Comparative study of field performance of micropropagated plants and stem cutting derived plants

Plants derived from nodal cuttings and micropropagated plants (rooted after three subcultures on shoot proliferation medium) were grown in field plots in rows at spacing of $60 \mathrm{~cm}$ with blocks of 24 plants in each plot. The field was mulched with field manure (soil and organic manure in 3:1 ratio) after planting and irrigated every 3 days. The stem cutting propagated and micropropagated plants were then picked up randomly from the rows and sacrificed ten each for 3 consecutive years to study the various morphological parameters such as height of the plant, thickness of the main shoot, total number of branches per plant, total number of leaves per plant, length of the internodes, weight of 100 leaves and leaf yield per plant.

\section{Results}

\section{Sprouting of the axillary buds in vitro}

Nodal explants of $3-4 \mathrm{~cm}$ bearing axillary buds were cultured on MS medium supplemented individually with 2,4-D for 
inducing sprouting. Nodal explants having greenish axillary buds enveloped by $2-3$ whorls of scales on medium tender shoots responded efficiently for sprouting.

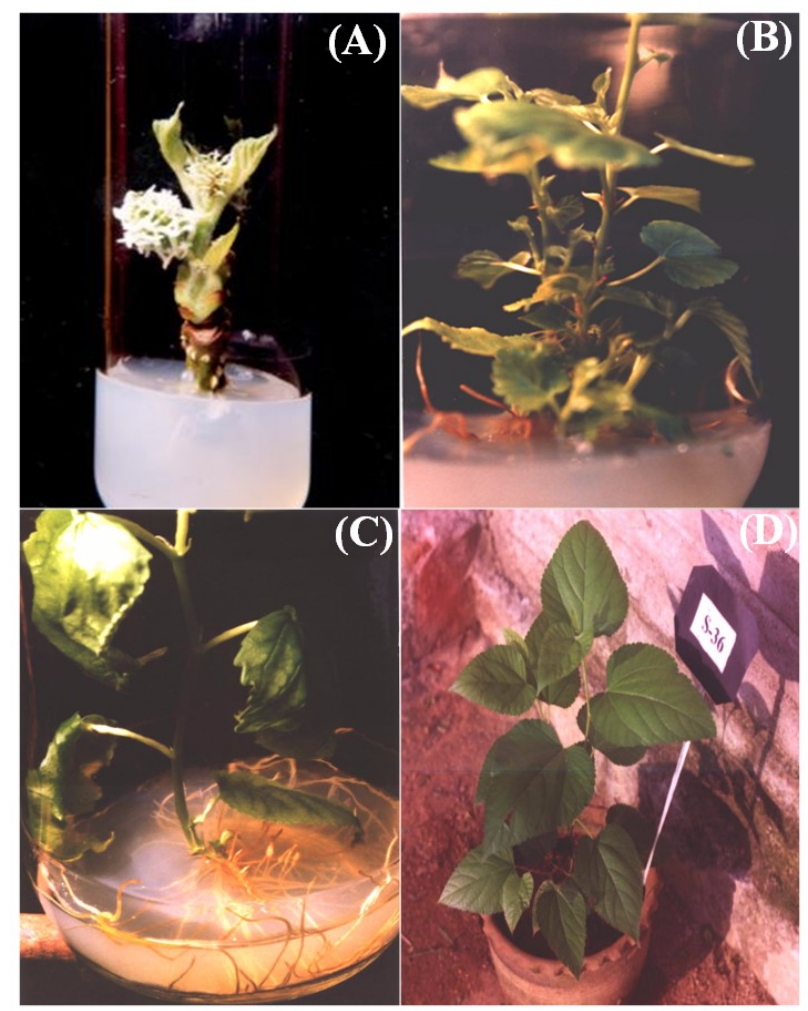

Fig 1: (A). Induction of sprouting from the axillary buds of S-36 cultivars of mulberry. (B). Multiple shoot induction from the axillary bud derived shoots of S-36 cultivars of mulberry after 30 days of culture on MS medium with $0.5 \mathrm{mg} / \mathrm{l}$ BAP. (C). Root induction from the axillary bud derived shoots of S-36 cultivar after 30 days of culture on MS medium with $1.0 \mathrm{mg} / 1$ 2,4-D. (D). Establishment of micropropagated plants derived from axillary buds of S-36 cultivar in pots containing garden soil and organic manure (3:1).

A high frequency of axillary bud sprouting of $83.3 \%$ from the nodal explants of S-36 cultivar was induced on medium supplemented with $0.3 \mathrm{mg} / 1$ of 2,4-D and sprouting occurred in 5 - 7 days. Multiple shoots were induced from the shoot tips differentiated from the axillary buds at a high frequency of $90.3 \%$ on MS medium with 0.5 $\mathrm{mg} / 1$ BAP. Medium supplemented with 1.0 $\mathrm{mg} / 12$,4-D favoured a high frequency of root induction of $100.0 \%$ from the shoots derived from the sprouted axillary buds and the roots were induced in 9-10 days (figure $1 \mathrm{~A}, \mathrm{~B}, \mathrm{C}$ ).

\section{Establishment of micropropagated plants in field}

Regenerated plants of S36 cultivar with well developed roots and 4-5 healthy leaves were transferred to pots containing soil and organic manure (3:1 ratio) and the humidity was maintained by covering with a plastic cover. The plants were acclimatized for 15-20 days and subsequently transferred to field. The survival frequency of the regenerated plants was more in rainy than in winter and summer seasons (figure $1 \mathrm{D}$ ).

Field performance of Micropropagated plants

The growth characteristics and vegetative morphology of micropropagated plants were compared with the plants raised through stem cuttings for three consecutive years (table 1). In vitro raised plants were healthier than stem cutting raised plants. The length of the stem cutting propagated plants was $506.3 \mathrm{~cm}$ in comparison to micropropagated plants which exhibited a length of 396.3 $\mathrm{cm}$ in the first year. The leaf area of the stem cutting raised plants was more in comparison to the micropropagated plants. The thickness of the main shoot of the stem cutting derived plants was more $(14.2-15.9 \mathrm{~cm})$ than the micropropagated plants $(9.4-11.0 \mathrm{~cm})$ when observed for three years. But, the number of branches/plant was more for micropropagated plants (12.3) and an enormous increase in the number of branches/plant was noticed in micropropagated plants at the end of $3^{\text {rd }}$ year (26.3). In contrast, the stem cutting derived plants exhibited a marginal increase in the number of branches/plant with 9.0 branches in first year and 12.7 in third year (figure $2 \mathrm{~A}$ and $\mathrm{B}$ ). The internodal distance of the micropropagated plants was lesser (4.5$4.9 \mathrm{~cm}$ ) than that of the stem cutting derived 
plants (6.2-6.8). The weight of the single leaf of the stem cutting raised plants was more compared to micropropagated plants in all three years. However, this did not alter the yield of micropropagated plants as they had more number of branches/plant (Table 1. Figure $2 \mathrm{C}$ and D).

Table 1: Field performance of micropropagated plants in comparison to stem cutting derived plants for three consecutive years.

\begin{tabular}{|c|c|c|c|c|c|c|c|c|}
\hline \multirow[b]{2}{*}{ 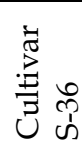 } & \multirow[b]{2}{*}{ 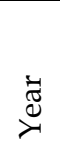 } & \multicolumn{7}{|c|}{ Morphological Characters } \\
\hline & & $\begin{array}{c}\text { Length of } \\
\text { the plant } \\
(\mathrm{cm})\end{array}$ & $\begin{array}{l}\text { Thickness } \\
\text { of the } \\
\text { shoot }(\mathrm{cm})\end{array}$ & $\begin{array}{c}\text { No. of } \\
\text { branches }\end{array}$ & $\begin{array}{l}\text { Total no. of } \\
\text { leaves/plant }\end{array}$ & $\begin{array}{l}\text { Length of } \\
\text { the inter- } \\
\text { node }(\mathrm{cm})\end{array}$ & $\begin{array}{c}\text { Weight of } \\
100 \text { leaves } \\
(\mathrm{gm})\end{array}$ & Yield / plant \\
\hline \multirow[t]{3}{*}{$\mathrm{CP}^{*}$} & $1^{\text {st }}$ & $506.3 \pm 3.7$ & $14.2 \pm 0.2$ & $9.0 \pm 0.6$ & $906.3 \pm 9.0$ & $6.2 \pm 0.1$ & $635.3 \pm 2.0$ & $5812.3 \pm 13.0$ \\
\hline & $2^{\text {nd }}$ & $581.3 \pm 2.4$ & $15.3 \pm 0.3$ & $11.3 \pm 0.9$ & $1140.3 \pm 26.5$ & $6.5 \pm 0.2$ & $764.7 \pm 2.0$ & $8393.7 \pm 4.2$ \\
\hline & $3^{\mathrm{rd}}$ & $613.3 \pm 3.4$ & $15.9 \pm 0.1$ & $12.7 \pm 0.7$ & $1530.0 \pm 21.4$ & $6.8 \pm 0.1$ & $843.3 \pm 2.0$ & $12254.2 \pm 17.7$ \\
\hline \multirow[t]{3}{*}{$\mathrm{MP}^{*}$} & $1^{\text {st }}$ & $396.3 \pm 0.9$ & $9.4 \pm 0.3$ & $12.3 \pm 0.9$ & $970.0 \pm 14.3$ & $4.5 \pm 0.1$ & $652 \pm 1.2$ & $6355.7 \pm 4.7$ \\
\hline & $2^{\text {nd }}$ & $406.0 \pm 1.7$ & $10.2 \pm 0.2$ & $16.0 \pm 1.5$ & $1642.0 \pm 18.6$ & $4.8 \pm 0.1$ & $772.0 \pm 1.2$ & $12051.7 \pm 8.2$ \\
\hline & $3^{\mathrm{rd}}$ & $463.7 \pm 2.1$ & $11.0 \pm 0.03$ & $26.3 \pm 1.2$ & $2012.0 \pm 17.6$ & $4.9 \pm 0.02$ & $862.7 \pm 1.5$ & $17294.3 \pm 23.9$ \\
\hline
\end{tabular}

$\mathrm{CP}^{*}$ - Stem cutting derived plant $\mathrm{MP}^{*}$ - Micropropagated plants Means followed by the same letter in a column are not significantly different $(\mathrm{p}<0.05)$ by Newman-Keul's multiple range test.

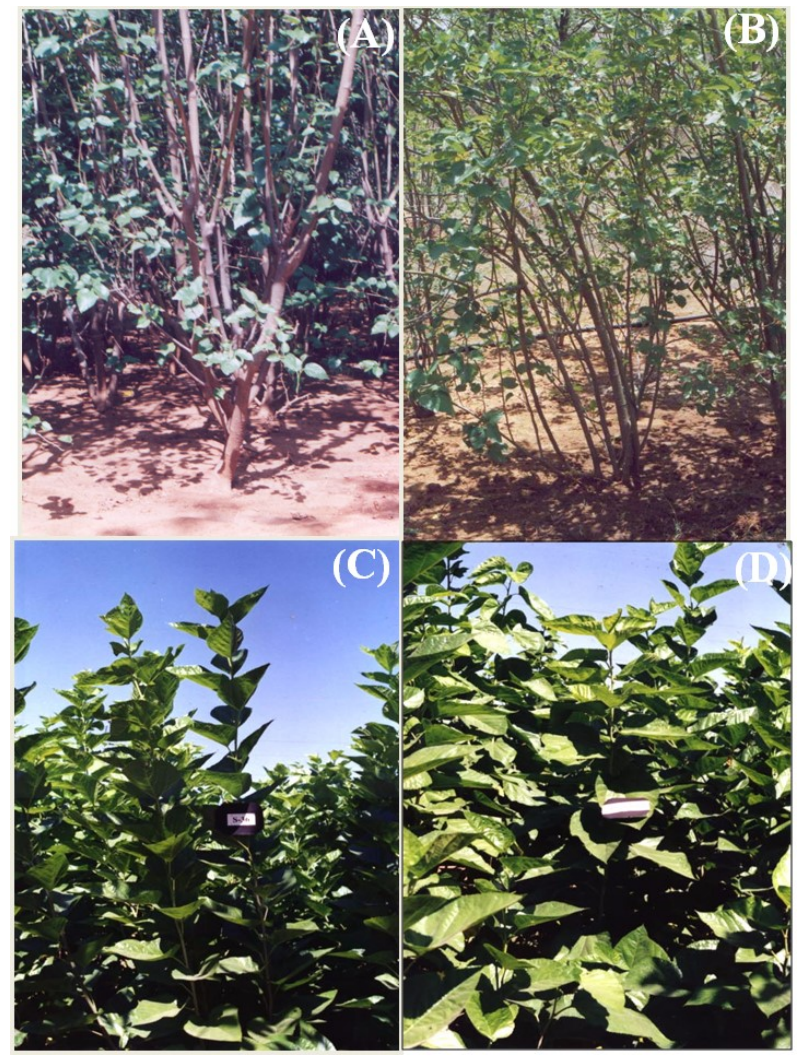

Fig 2: Comparison of field performance of oneyear old plants of S-36 cultivar established from nodal cuttings with micropropagated plants. (A) Stem cutting raised plants, (B) Micropropagated plants. (C \& D) Establishment of both stem cutting raised plants and micropropagated plants after three years.

\section{Discussion}

Micropropagation methods are specifically applicable to species for which clonal propagation is required. Mulberry is a highly heterozygous plant and propagation through axillary buds would ensure genetic uniformity and stability among the regenerants. It offers several advantages which include the ease of obtaining explant material, a strong tendency for profuse multiple bud induction, the relative ease with which the shoots could be induced to root and the high percentage of ex vitro plant survival after acclimatization.

In S-36 cultivar, high frequency of sprouting $(83.3 \%)$ was induced on $0.3 \mathrm{mg} / 1$ 2,4-D supplemented medium. Shoot multiplication was maximum when BAP at $0.5 \mathrm{mg} / 1$ was used for shoot multiplication of axillary bud derived shoots with induction of 6.5-7.5 shoots at the end of 30 days. Medium supplemented with high levels of auxins (1.0 $\mathrm{mg} / \mathrm{l})$ was found to be effective for shoots differentiated from the axillary buds

The number of plants, which are successfully transferred from tissue culture vessels to soil conditions, can only effectively measure the success of any micropropagation system. An important requirement for plants 
produced in vitro is that the plants must be genetically identical to the source plants. It was observed that, in vitro raised plants of S36 cultivar were much vigorous and exhibited more number of branches than the stem cutting raised plants which may be due to their previous exposure to cytokinins in the culture medium. Maximum height was recorded in stem cutting derived plants compared to micropropagated plants for three consecutive years. But Murashige (1978) and Zaman et al., (1997) observed a reversed trend of more height of micropropagated plants than the conventionally propagated plants from stem cuttings. In the present study, the thickness of the shoot was more $(14.2-15.9 \mathrm{~cm})$ for the stem cutting derived plants than in micropropagated plants $(9.4-11.0 \mathrm{~cm})$. The leaf number of micropropagated plants was more (6355.7-17294.3) compared to field propagated plants (5812.3-12254.2), but leaf area of micropropagated plants was less in comparison to stem cutting derived plants. Even though the weight of the single leaf was more in stem cutting propagated plants, the yield of micropropagated plants was high due to the presence of more number of branches. The internodal distance was less in micropropagated plants and hence, the leaves were closely present on the shoots. Pandey and Singh (1989) also found the same type of morphogenic expressions while comparing the in vitro raised and seedling raised plants of Carica papaya. Jain and Datta (1992) compared the performance of the in vitro grown plants of Morus bombycis cultivar, Shimanochi with vegetatively grown saplings for various morphological characters like leaf shape, petiole length, area of leaf lamina and internodal distance. The study revealed that in vitro grown plants did not exhibit any significant quantitative variation as compared to the conventionally grown plants, indicating the varietal multiplication to be of true-to-type. Morrison et al., (2000) reported that micropropagated plants of
Vaccinium augustifolium that did not result from subcultures had stem characteristics more similar to stem cuttings than to seedlings, with less branching than seedlings and fewer vegetative buds for burying. They inferred that subculturing on cytokinin-rich media apparently induces the juvenile branching characteristics that provide micropropagated plants with the desirable morphological and growth habits of seedlings with the benefits associated with asexual propagation. Increased vigour of microclones under field condition has also been reported for apple (Zimmerman et al., 1986), thornless blackberry (Swartz et al., 1983). The plants regenerated via micropropagation are derived from characteristic organized meristems or meristematic cells. These cells are by nature genetically stable and less prone to mutational changes (Vasil1994). Thus, the results obtained in the present study clearly demonstrated that micropropagation gave rise to superior clonal populations with respect to number of branches/plant and leaf yield/plant that will be suitable for the mass production of plants.

\section{Acknowledgements}

We gratefully acknowledge University Grants Commission, New Delhi for providing financial assistance under unassigned grant scheme to carry out this work. DSVC is thankful to University Grants Commission, New Delhi for the award of extended SRF Fellowship.

\section{Reference}

Bhau B.S. 1999. Tissue culture studies of some difficult-to-root temperate varieties of Morus alba (L.) and Morus multicaulis (PERR.), Ph.D. Thesis, Jammu University, Jammu

Bhojwani S.S. 1992. Plant tissue culture and its relevance to mulberry breeding. Brain storming meeting on genetics and 
biotechnology of silkworm and mulberry, CSRTI, Mysore 1-11

Biondi S, and Thorpe T.A. 1982. Clonal propagation of forest tree species. In: Proceedings of COSTED symposium (ed) A Rao "Tissue culture of economically important plants", COSTED and Asian Network of Biological Sciences, Singapore 197-204.

Chattopadhyay S, Chattopadhyay S, Datta S.K. 1990. Quick in vitro production of mulberry (Morus alba L.) plantlets for commercial purpose. Indian Journal of Experimental Biology, 28: 522-525.

Chitra D.S.V. and Padmaja G. 1999. Clonal propagation of mulberry (Morus indica L. cultivar M-5) through in vitro culture of nodal explants, Scientia Horticulture, 80: 289-298

Chitra D.S.V. and Padmaja G. 2002. Seasonal influence on axillary bud sprouting and micropropagation of elite cultivars of mulberry, Scientia Horticulture, 92: 55-68

Das B.C. 1983. Mulberry taxonomy, cytogenetics and breeding, National Seminar on Silk Research and Development, March 10-13 Bangalore

Hossain M, Rahman S. M, Zaman A, Joader O. I and Islam R. 1992. Micropropagation of Morus laevigata Wall from mature trees, Plant Cell Reports, 11: 522-524

Jain A. K and Datta R. K. 1992. Shoot organogenesis and plant regeneration in mulberry (Morus bombycis Koidz): factors influencing morphogenetic potential in callus cultures, Plant Cell Tissue Organ Culture, 29: 43-50

Mhatre M, Bapat V.A and Rao P.S. 1985. Regeneration of plants from the culture of leaves and axillary buds in mulberry (Morus indica L.), Plant Cell Reports, 4: 7880

Morrison S, John M. S and Litten W. 2000. Morphology, growth and rhizome development of Vaccinium angustifolium Ait. Seedlings, rooted softwood cuttings and micropropagated plantlets, Horticulturae Science, 35: 738-741

Murashige T. 1978. The impact of plant tissue culture in agriculture. In Frontiers of plant tissue culture, (ed) Thorpe TA, University Calgary Press, Canada 15-26

Murashige T and Skoog F. 1962. A revised medium for rapid growth and bioassays with tobacco tissue cultures, Physiologia Plantarum, 15: 473-497

Ohyama K and Oka S. 1987. Mulberry, In Cell and Tissue Culture in Forestry, (ed) Bonga J M and Durzan D J (Martinus-Nijhoff Publishers), The Netherlands pp 272-284

Pandey R.M and Singh S.P. 1989. Field performance of in vitro raised plants, Indian Journal of Horticulture, 33: 1-7

Pattnaik S.K and Chand P.K 1997. Rapid clonal propogation of three mulberries, Morus cathayana Hemsl., M. lhou Koiz. and M. serrata Roxb., through in vitro culture of apical shoot buds and nodal explants from mature trees, Plant cell Reports, 16: 503508

Sharma K.K and Thorpe T.A. 1990. In vitro propagation of mulberry (Morus alba L.) through nodal segments, Scientia Horticulture, 42: 307-320

Swartz H.J, Galletta G.J and Zimmerman R.H. 1983. Field performance and phenotypic stability of tissue culture propagated thronless blackberries, Journal American Society Horticulture Science, 108: 285-290

Tewari P.K, Sarkar A, Kumar V and Chakraborti S. 1995. Rapid in vitro multiplication of high yielding mulberry (Morus spp.) Genotypes V-1 and S-34, Indian Journal of Sericulture, 34: 133-136

Thorpe T.A. 1983. Biotechnological applications of tissue culture to forest tree improvement, Biotechnology Advances, 1: 263-278

Vasil I.K. 1994. Automation of plant propagation, Plant Cell Tissue Organ Culture, 39: 105-108

Yadav U, Madan L and Jaiswal V.S. 1990. Micropropagation of Morus nigra L. from 
shoot tip and nodal explants of mature trees, Scientia Horticulture, 44: 61-67

Zaman A, Islam R and Joarder O.I. 1997. Field performance and biochemical evaluation of micropropagated mulberry plants, Plant Cell Tissue Organ Culture, 51: 61-64

Zimmerman R.H, Griesbach R. J, Hammerschlag F. A and Lawson R.H. 1986. Tissue culture as a plant production system for horticultural crops, (Martinus Nijhoff Publishers), Dordrecht 